\title{
KFBD
}

Karadeniz Fen Bilimleri Dergisi

The Black Sea Journal of Sciences

ISSN (Online): 2564-7377

Araștırma Makalesi / Research Article

\section{Genel Amaçlı Kübik Bir Robot Tasarımı ve Uygulaması}

\author{
Halil GÖK ${ }^{1}$, Ömür AKYAZI², Erdinç ŞAHİN $3^{3 *}$ \\ 1,2,3Karadeniz Teknik Üniversitesi, Of Teknoloji Fakültesi, Enerji Sistemleri Mühendisliği Bölümü, Trabzon, Türkiye
}

*Sorumlu Yazar: esahin@ktu.edu.tr

Geliş Tarihi: 03.04.2020

Kabul Tarihi: 04.05 .2020

\section{Öz}

Bu çalışmada genel amaçlı kübik bir robot tasarımı ve uygulaması gerçekleştirilmiştir. Dört adet küpten meydana gelen kübik robot, içerisinde var olan altı adet DC servo motor ile eş zamanlı hareketler, ileri-geri pozisyon değiştirme ve yükselme-alçalma hareketleri yapabilmektedir. Dört küpten ikisi birbirine bağlı ve merkezde yer almakta, serbest hareket eden diğer iki küp ise merkezin sağına ve soluna yerleştirilmiştir. Yazılım geliştirme kartı olarak Arduino nano kullanılmıştır ve bu kart merkez küplerde yer almaktadır. Tasarlanan robot internet üzerinden (web sayfası) mobil ara yüz ile açık çevrim kontrol edilmektedir. Robotun yapabildiği hareketlerin videosuna çalışmanın sonuç bölümünde verilen net adresinden ulaşılabilir.

Anahtar Kelimeler: Kübik Robot, Web Tabanlı Açık Çevrim Denetim, Servo Motor Uygulaması

\section{Design and Implementation of a General Purpose Cubic Robot}

\begin{abstract}
In this study, a general purpose cubic robot design and application has been realized. The cubic robot consisting of four cubes can perform simultaneous movements, forward-backward position change and ascending-descending movements by using six DC servo motors. Two of the four cubes are connected each other and located in the center of the robot, while the other two free-moving cubes are placed to the left and right of the center. Arduino nano is used as software development card and this card is located in the center cubes. The designed robot is open loop controlled via a mobile interface (web page). The video of the movements of the robot can be accessed from the net address given in the conclusion section of the study.
\end{abstract}

Keywords: Cubic Robot, Web-Based Open Loop Control, Servo Motor Application 


\section{Giriş}

Robotik sistemlerin tanımı Amerikan Robot Enstitüsü tarafından geçmiş zamanda genel bir amaç için tasarlanmış programlanabilir ve çok fonksiyonlu manipülatörler olarak belirtilse de günümüzde robot tanımı için kullanılan yaygın alg1; bir insanı sadece fiziksel olarak değil, aynı zamanda zekâ ve kişilik ile taklit etmek için manipüle edilebilir bir sistemdir (Gu, 2013). Teknolojik gelişmeler neticesinde robotik sistemler üretim endüstrisi, savunma sanayi, sağlık sektörü ve günlük hayatımızın birçok alanında sıkça kullanılmaktadır (Şahin ve ark., 2012; Gündoğdu ve ark.,2013). Robotik sistemlerin kullanım alanlarına göre sınıflandırılması üzerine yapılan bir çalışmada endüstriyel robotlar, mobil robotlar, insansı robotlar, çoklu robotlar, sürü robotları, mikro-nano robotlar ve bunun gibi birçok robot türü farklı başlıklar altında verilmiştir (Gürgüze ve ark., 2019).

Robotik sistemlerin modellenmesi ve tasarımının yanında denetimi ve kullanılan algoritma tipi de önemli bir yer tutmaktadır (Akyazı ve ark., 2017). Parçacık sürü optimizasyonu, genetik algoritma, gri kurt algoritması, ateş böceği algoritması, karınca kolonisi algoritması, Kalman filtresi, bulanık mantık, petri ağları, Markov zinciri, Monte Carlo metodu ve levy uçuşu robot sistemlerinde uygulanan bazı algoritmalardır (Gürgüze ve ark., 2019). Denetleyici yöntemi olarak da araştırmacılar birçok konu çalışmaktadır. Robotik sistem denetiminde genel olarak kuvvet denetimi, tork denetimi, gürbüz denetim, uyarlamalı denetim ve akıllı denetim başlıkları karşımıza çıkmaktadır (Lewis ve ark., 2003). Referans yolun veya sinyalin takibi ile istenilen hareketin manipülatörlere yaptırılmasında genellikle AC veya DC servo motorlar eyleyici olarak kullanılmaktadır (Lewis ve ark., 2003). Bunun yanında bazı yüksek fiziksel güçlü uygulamalarda hidrolik eyleyiciler tercih edilmektedir.

$\mathrm{Bu}$ çalışma ile amacımız referans hareketleri izleyebilecek, gerektiğinde istenilen pozisyona kitlenip kalabilecek ve önüne çıkan engelleri aşabilecek genel amaçlı kübik bir robot sistemin tasarımıdır. Projenin fiziksel tasarım sürecinde, elektronik devre tasarımında ve yazılım uygulamasında sıra ile SolidWork programı, Proteus Programı ve Arduino geliştirme kartı kullanılmıştır. Dört adet küpten meydana gelen robot altı adet servo motor içermektedir. İstenilen referans hareketlerin gerçekleştirilmesi için bazı matematiksel hesaplamalardan yararlanıldı. Tasarlanan robot bir web sayfası üzerinden kontrol edilmektedir. Kontrol panelinde manuel ve otomatik kontrol seçenekleri yer almaktadır. Gelecek başlıklarda sıra ile kübik robotun fiziksel tasarlanma süreci, denetim süreci ve sonuçlar yer almaktadır. 


\section{Kübik Robotun Tasarımı}

\subsection{Fiziksel Parçaların Üretimi}

Robotu oluşturan küplere ait tasarımlar ve ölçüler aşağıda Şekil 1'de görülmektedir. Küpler yapboz gibi takılıp birbirine montajlanmaktadır. Her küpe takılan kapaklar aynı boyuttadır. Kapaklar $3.2 \mathrm{~mm}$ çaplı vidalar ile tutturulmuştur. Kolların tasarımı motorun ucuna gömülecek biçimde yapılmıştır. Bu parçalar SolidWork programında tasarlanmış ve 3 boyutlu yazıcı ile basılmıştır. Aşağıda verilen parçalar birleştirilerek Şekil 2'de görülen robotun son hali elde edilmiştir.

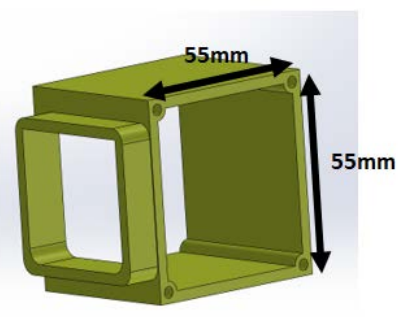

(a)

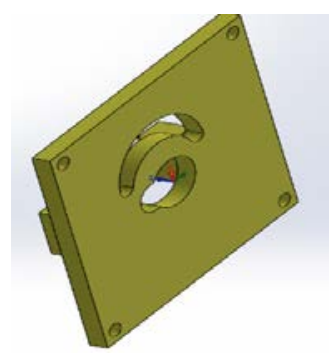

(d)

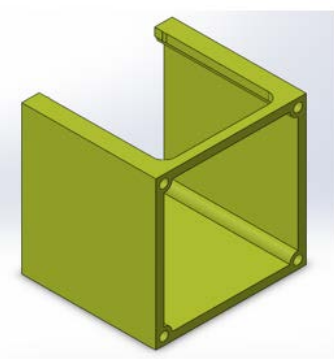

(b)

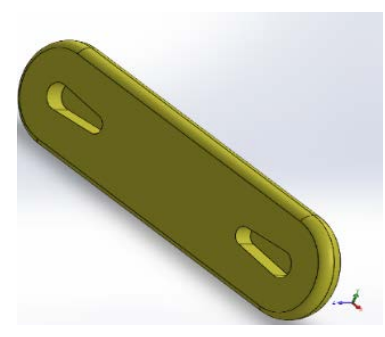

(e)

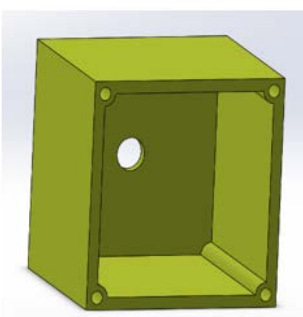

(c)

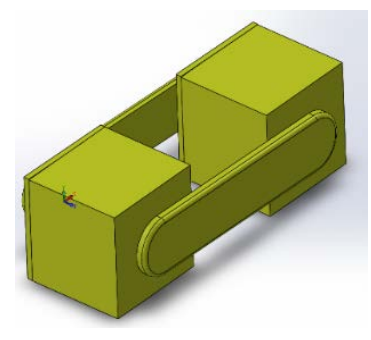

(f)

Şekil 1. Küplere ait tasarımların görünümleri (a,b,c), kapak ve kol çizimleri (d,e), örnek bir bağlantı şekli (f).

\subsection{Donanım Kismı}

Bu başlık altında tasarlanan robota ait donanımsal parçalar hakkında bilgi verilmektedir. Robot hareketleri SG-90 servo motor ile sağlanmaktadır. Motora ait bağlantı şekli ve Arduino uygulamaları ile ilgili detaylı bilgiye (Cameron, 2019)'ten ulaşılabilir. Devrenin güç gereksinimi MT3608 modülü üzerinden sağlanmaktadır. MT3608 modülü yüksek verimli, çıkış gerilimi ayarlanabilen yükselten tip bir DA-DA çeviricidir (URL-1, 2020). NodeMCU ESP8266 ünitesi düşük güç tüketimiyle çalışan geliştirilebilir bir mikrodenetleyicidir. Üzerinde var olan WiFi aparatıyla nesnelerin interneti olarak bilinen IOT tabanlı ürün geliştirmede kullanılmaktadır (Patel ve ark., 2019). Proje kapsamında tasarlanan robotun denetimi bir web sayfası üzerinden gerçekleştirileceği için bu ürün sisteme dâhil 
edilmiştir. NodeMCU ESP8266 ünitesine ait bağlantı şekli ve detaylar (URL-2, 2020)'de verilmektedir. Donanım kısmına ait alt sistemler delikli plaket üzerinde birbirine bağlanmıştır. Donanımsal bağlantıya ait Proteus programı ile çizilen şematik gösterim Şekil 3'te verilmektedir.

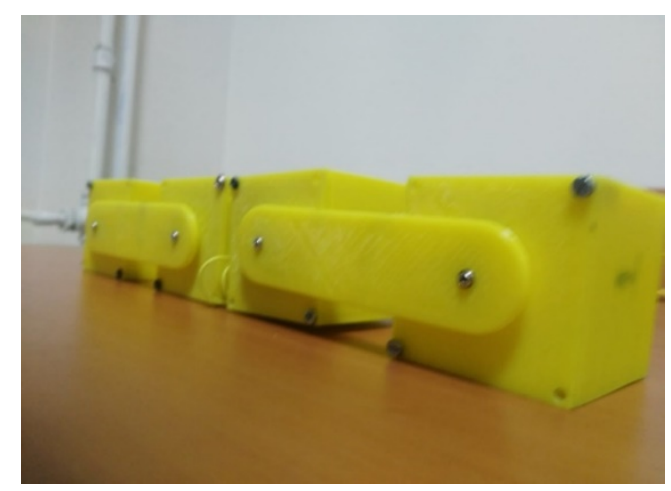

(a)

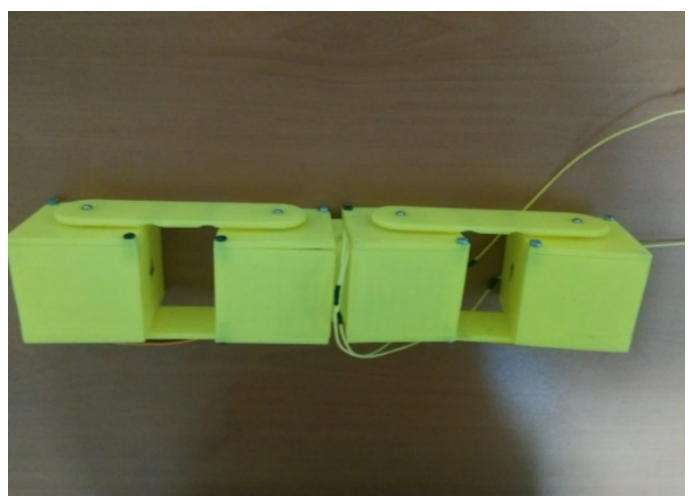

(b)

Şekil 2. Kübik robotun (a) yandan ve (b) üstten görünümü.

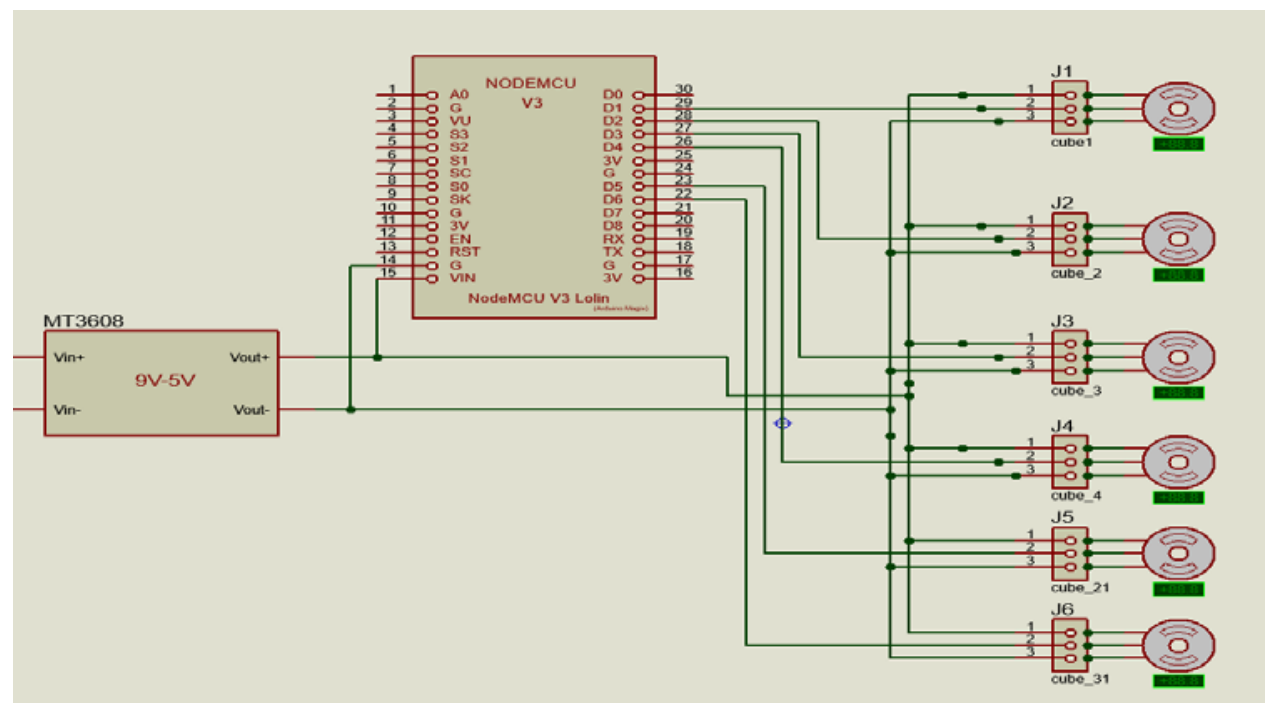

Şekil 3. Devre bağlantılarının gösterildiği Proteus programı çizimi. 


\subsection{Yazılım Kısmı}

Servo motorlar darbe genişlik modülasyonu (PWM) sinyalleri ile çalışmaktadırlar. Bu PWM sinyalleri kablosuz veya kablolu olarak bir mikro denetleyici yardımıyla üretilebilir. Üretilen pals sinyalinin genişliğine göre servo motor pozisyon değiştirmektedir. Pozisyonun devamlılığı için motora uygulanan sinyalin tekrar edilmesi gerekmektedir. Motor tipine göre motora uygulanacak giriş sinyalinin genişlik limitleri değişkenlik gösterebilir. Genellikle alt ve üst darbe genişliği 1-2 ms aralığındadır (URL-4, 2020). Aşağıda verilen şekilde giriş sinyallerine göre servo motorun aldığı pozisyonlar örnek olarak gösterilmektedir.

(a)

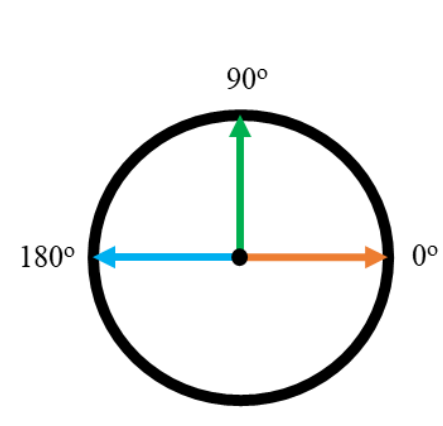

(b)

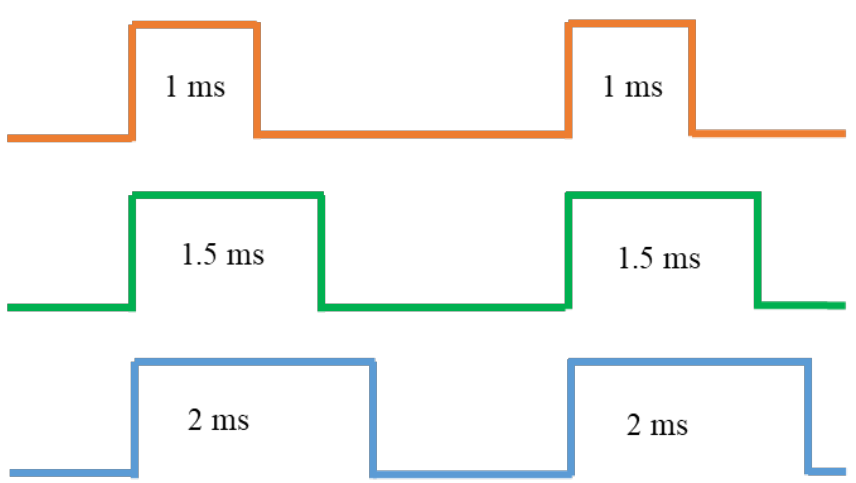

Şekil 4. Giriş sinyallerine göre servo motorun aldığı pozisyonlar. (a) Servo motor konumu, (b) giriş sinyali.

Önerilen robotun gerçekleştirme aşamasında Şekil 5’te görüldüğü gibi küplerin içindeki servo motorlara sembolik sayısal değişkenler $(1,2,21,3,31,4)$ atanmıştır. Bu sayısal değerler robota hareket kabiliyetini sağlayacak olan servo motorları temsil etmektedir. Belirli hareketleri veya sistemin doğru bir şekilde istenilen hareketleri yapabilmesi için ilgili küpün içindeki servo motorun istenilen yönde hareket ettirilmesi gerekmektedir. 2. ve 3. küpte 2 'şer adet servo motor bulunmaktadır. Bu karşılıklı olan küpler zıt yönde dönmektedirler. Eğer 3. Küp ile ilgili hareket yapılacaksa, örneğin 3 numaralı motor " 0 o konumunda" ise diğer 31 numaralı motorda " $180^{\circ}$ konumunda" olmalıdır. Robotun hareket kabiliyetini artırmak için servo motorların başlangıç pozisyonunda 1 . ve 4 . küpler “ $0^{\circ}$ konumunda”, 2. ve 3 . küpler " $135^{\circ}$ konumunda" olacak şekilde ayarlanmıştır. 


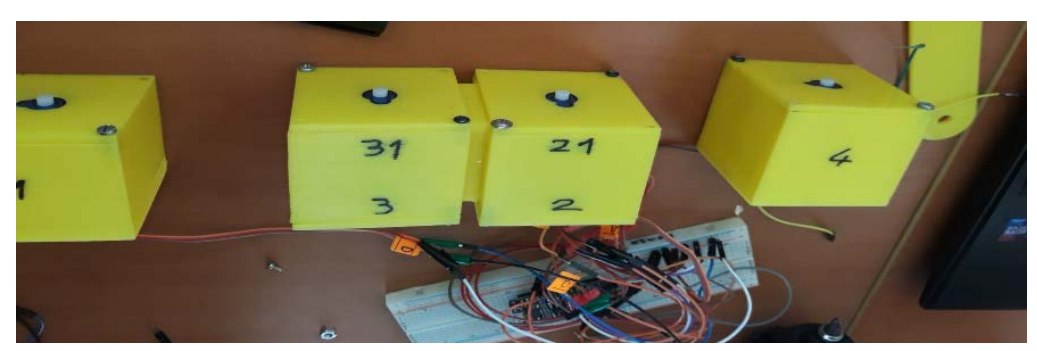

Şekil 5. Küplere atanmış sembolik sayısal değerler.

Yazılan kod ile tüm servo motorları bir değişken (i) üzerinden kontrol edilmektedir. Bir döngü başlatarak motorun hareket işlemleri sağlanmaktadır. Referans verilen motor hareketlerinin gerçekleştirilebilmesi için motorların istenilen konumlara gitmesi gerekmektedir.

Önerilen robota yaptırılacak ilk hareket yükselme-alçalma hareketidir. Başlangıç konumundan başlatılarak her farklı harekette motorların (i) değişkeni üzerinden hareket açılarını tamamlaması gerekmektedir. Kübik robot 1.ve 4. küpü kaldırma hareketini yaptıktan sonra 2500 milisaniye bekletilmekte ve sonrasında kalkan merkez küpleri indirmek için (i) değişkenindeki değerler yani motorun konumları başlangıç konumuna gelene kadar azaltılmaktadır. Bu hareketi ifade eden akış diyagramı Şekil 6’da verilmektedir.

Kübik robotun ikinci referans hareketi ileri-geri gitme hareketidir. Bu hareket yapılırken 1. ve 4. motorlar yere temas etmektedir ve merkez küpleri yerden yüksekte konumlandırılmıştır. Bu harekete ait akış diyagramı Şekil 7’de sunulmuştur.

Son olarak ise kübik robota dik durma hareketi yaptırılmıştır. Bu hareket 4 adımda gerçekleştirilmiştir. Sıra ile küplerin senkronize çalışması dik durma hareketini sağlamaktadır. İlk adım da 2. ve 3. Küpün yükselmesi hareketi vardır. Bu durumda 2. motor ile 21. motor ve 3. motor ile 31. motor birbirinin tersi hareket edecek şekilde çalışmalıdır. Yani 2. motor (i) konumunda iken 21. motor (180-i) konumunda olmalıdır. Bu hareket için yazılan döngü Tablo 1 (a)'da verilmektedir. Dik durma hareketinin 2. adımında denge pozisyonuna geçilmektedir. Bu adımda ă̆ırlık merkezi dengelenmeye çalışılmaktadır. Bu adım için yazılan döngü de Tablo 1 (b)'de gösterilmektedir. 3. adım kübik robotun tam dikey pozisyonuna geçmeden bir önceki adımdır. Bu adımda 1. küp dengeyi sağlamak amacıyla yukarı kaldırılır. Son adımda ise tam bir denge halinin sağlanması için tüm küpler senkronize şekilde çalışarak kübik robotun dikey konumda durması gerçekleştirilir. Bu durumun sağlanması için her bir küp farklı açıya gitmektedir. Bu açıların hesabında iki noktası bilinen doğru denklemi kullanılmıştır. Son iki adıma ait döngü hesapları sıra ile Tablo 1 (c) ve (d)'de gösterilmiştir. 4. adımda tam dikey pozisyona getirilen kübik robota yukarıda anlatılan işlemlerin tersi yönde uygulanması ile yatay konumu geri gelmektedir. 
Tablo 1. Kübik robotun dikey konumu için hesaplanan motor konumları

\begin{tabular}{|c|c|}
\hline (a) & (b) \\
\hline $\begin{array}{l}\text { for(i=135;i }>=45 ; \mathrm{i}--) \\
\text { cube_1.write(0);cube_4.write(0); } \\
\text { cube_2.write(i); } \\
\text { cube_21.write(180-i); } \\
\text { cube_3.write(i); } \\
\text { cube_31.write(180-i); } \\
\text { end }\end{array}$ & $\begin{array}{l}\text { for(i=45;i>=14;i--) } \\
\text { cube_4.write(49-i); } \\
\text { cube_2.write(i); } \\
\text { cube_21.write(180-i); } \\
\text { cube_3.write(90-i); } \\
\text { cube_31.write(90+i); } \\
\text { end }\end{array}$ \\
\hline (c) & (d) \\
\hline $\begin{array}{l}\text { for }(\mathrm{i}=70 ; \mathrm{i}<=180 ; \mathrm{i}++) \\
\quad \text { cube_3.write(i); } \\
\text { cube_31.write(180-i); } \\
\text { end }\end{array}$ & $\begin{array}{l}\text { for }(\mathrm{i}=20 ; \mathrm{i}<=135 ; \mathrm{i}++) \\
\text { cube_2.write }(\mathrm{i}+2) ; \\
\text { cube_21.write }(178-\mathrm{i}) ; \\
\text { y=(41.08696-((0.30435)*i)); } \\
\text { cube_4.write }(\mathrm{y}) ; \\
\text { cube_3.write }((4320-9 * \mathrm{i}) / 23) ; \\
\text { cube_31.write }(180-(4320-9 * \mathrm{i}) / 23) \text {; } \\
\text { end }\end{array}$ \\
\hline
\end{tabular}

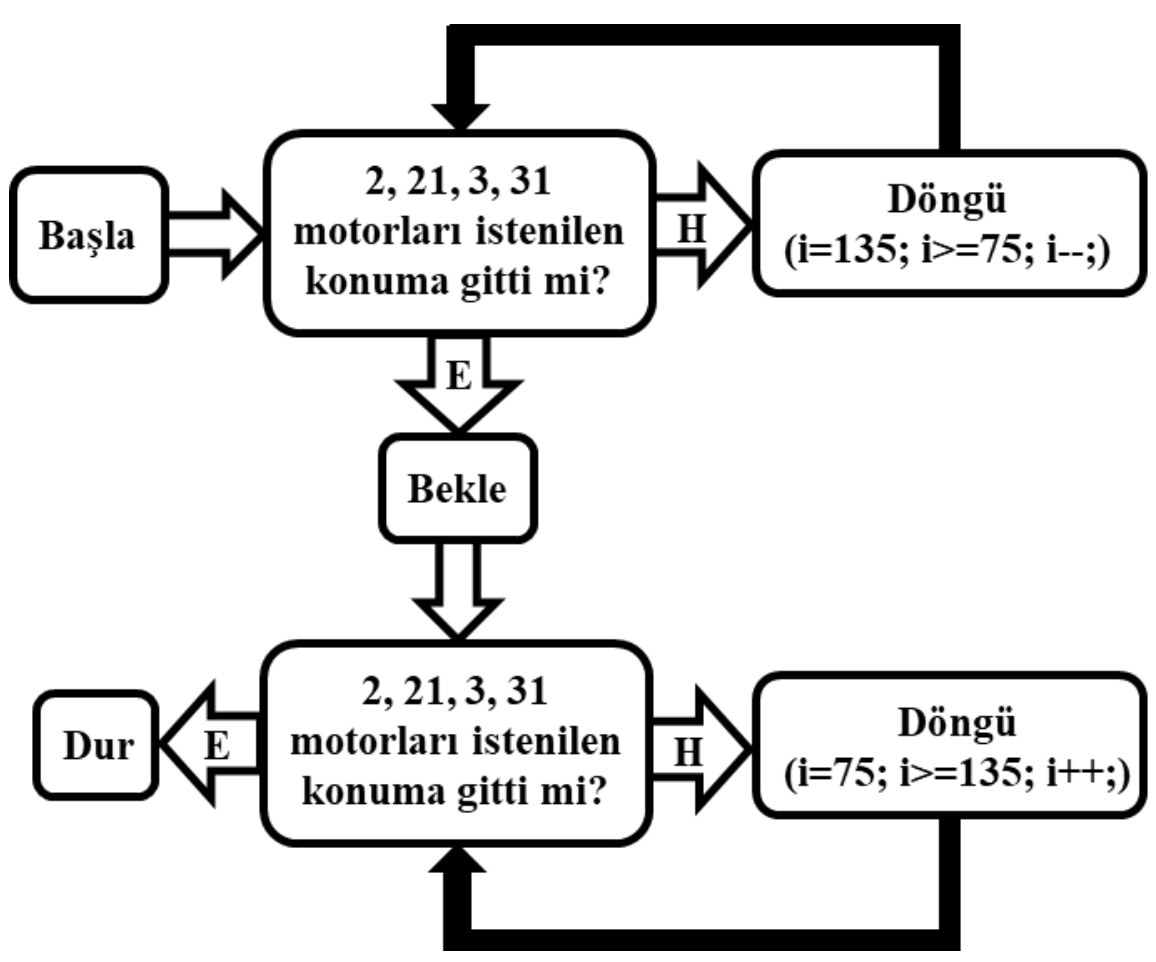

Şekil 6. Kübik robotun yükselme-alçalma hareketlerini ifade eden akış diyagramı. (H: Hayır, E: Evet) 


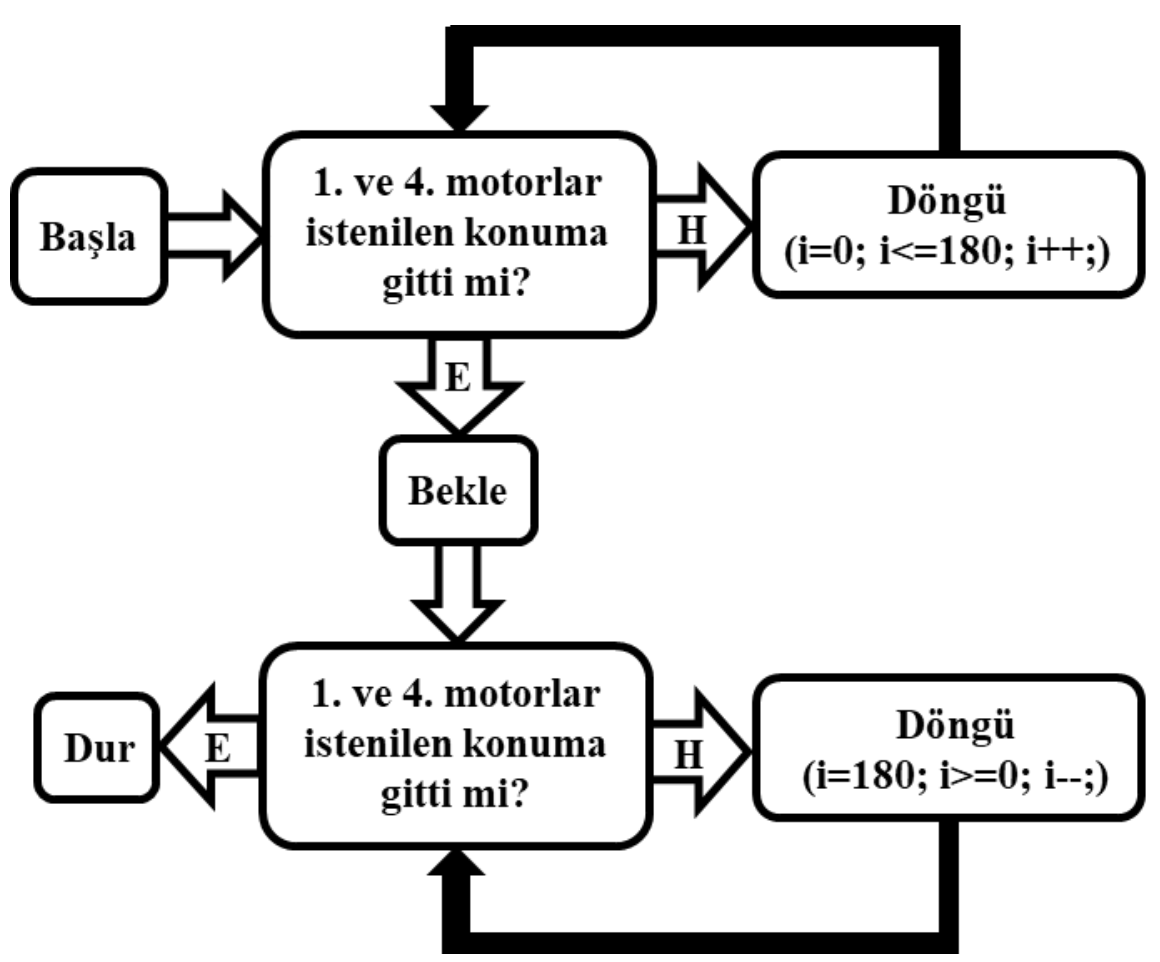

Şekil 7. Kübik robotun ileri-geri gitme hareketlerini ifade eden akış diyagramı.

\subsection{Kübik Robotun İnternet Sayfası Üzerinden Denetimi}

Kullanılan Wi-Fi ve denetleyici kartının IP adresi ile bir net sayfası oluşturma özelliğinden yararlanarak Arduino kartında hem internet sayfamızın tasarımına hem de projenin işleyen kodlarına tek bir sistem içerisinde yer verilmiştir. Web sayfasını oluştururken yazılan HTML kodları Arduino programı içerisinde bir blok halinde paketlenip internet ağına gönderilmektedir. Bu başlık altında yapılan işlemlere (URL-3, 2020)'den detaylı bir şekilde ulaşılabilir. Tasarımı yapılan sistemin görünümü Şekil 8’de verilmektedir.

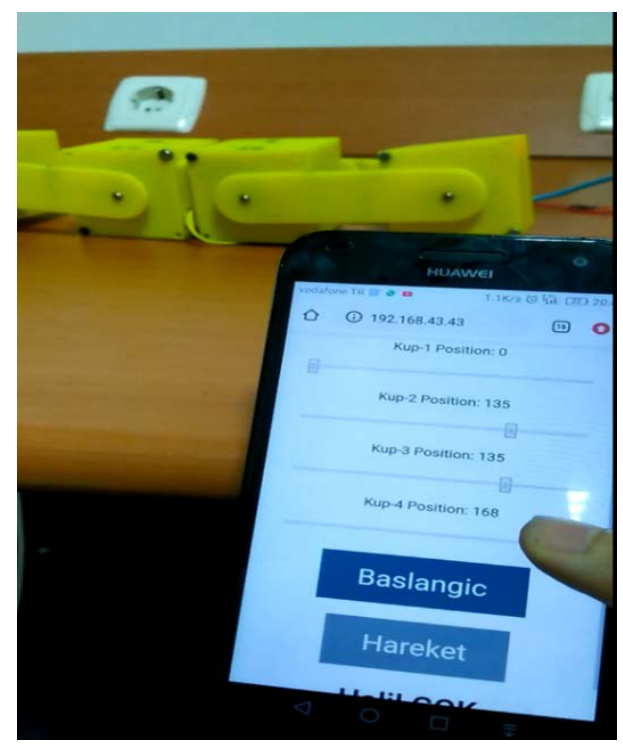

Şekil 8. Kübik robotun internet üzerinden denetimi. 


\section{Tartışma ve Sonuç}

Kübik robot projesinde yatay ve düşey eksenleri üzerinde istenilen hareketler başarı ile gerçekleştirilmiştir. Bu hareketlerin videosuna aşağıda verilen linkler üzerinden ulaşılabilir.

(https://www.youtube.com/watch?v=2sNsvLFiqKE, https://www.youtube.com/watch?v=BWYNSP3ynPg). Proje süresince yazılım, tasarım, donanım olarak 3 ayrı bölümde detaylı çalışmalar yapılmıştır. Önerilen robot kübik yapıda olup servo motorlar ile küplerimiz hareket etmektedir. Bu sistem veya benzeri genel amaçlı sistemler doğrudan veya dolaylı proje geliştiriciler tarafından bir ürünü ortaya koyarken kullanılabilir. Kübik robot projesinde istenen hareketler doğrudan internet ara yüzünden mikrodenetleyiciye iletilmektedir. Haberleşme ve motora iletilen sinyaller nodeMCU kartı ile sağlanmaktadır. Projede kullanılan servo motorlar 180 derece (adım) gidebilmektedir. Bu durum ilerigeri hareketlerini sınırlandırmaktadır. Maliyet açısından uygun olması ve kolay ulaşılabilirliği nedeniyle servo motor olarak SG90 modeli seçilmiştir. Ayrıca motor yük üzerinde iken bazı hareketlerin gerçekleştirilmesinde titreme sorunu ile karşıllaşılmıştır. Bu projede motor seçimi step motordan yana kullanılsaydı, sınırsız adım sayısı ile ileri-geri yön hareketleri ve dik durma hareketi daha başarılı bir şekilde titreme olmaksızın yapılacaktı.

Kübik robot projesinde hedefimiz drone, arazi araçları, savunma sanayiye dönük sistemler üzerinde geliştirilebilir, iyileştirilebilir çalışmalara destek vermektir. Ön beceri, temeller, sistem dinamiği, tasarım, algoritma tasarlama, ürün geliştirme süreci gibi yoğun vakit harcanan çalışmalar bu projede başarı ile gerçekleştirilmiştir.

\section{Kaynaklar}

Gu, E.Y.L., (2013). Introduction to Robotics and Digital Human Modeling. A Journey from Robot to Digital Human, Modeling and Optimization in Science and Technologies, vol 1., 1-13, Springer, Berlin, Heidelberg

Şahin, İ., Yalvaç, M., (2012). Kablosuz Kontrol Edilebilen Mobil Araştırma Robotu. e-Journal of New World Sciences Academy, 7 (1), 340-347.

Gündoğdu, K., Yüceldağ, İ., (2013). Ses veya Arayüz Yardımı ile Kontrol Edilebilen Mobil Robot Kol Tasarımı. Düzce Üniversitesi Bilim ve Teknoloji Dergisi, l (1), 24-31.

Gürgüze, G., Türkoğlu, İ., (2019). Kullanım Alanlarına Göre Robot Sistemlerinin Sınıflandırılması. Firat Üniversitesi Mühendislik Bilimleri Dergisi, 31(1), 53-66.

Akyazı, Ö., Aktoğan, A., Başar, B., İnan, T.A., (2017, Eylül). Remote Control of Arduino Based Caterpillar Robot. 2nd International Conference on Advanced Engineering Technologies- ICADET2017 (546-551). Bayburt.

Gürgüze, G., Türkoğlu, İ., (2019). Robot Sistemlerinde Kullanılan Algoritmalar. Türk Doğa ve Fen Dergisi, 8(1), 17-31.

Lewis, F. L., Dawson, D. M., Abdallah, C. T., (2003). Robot manipulator control: theory and practice. CRC Press.

Cameron, N., (2019). Servo and Stepper Motors. In: Arduino Applied. Apress, Berkeley, CA 
URL-1: https://prom-electric.ru/media/MT3608.pdf, (Erişim Tarihi: 7 Şubat 2020).

Patel, A., Devaki, P., (2019). Survey on NodeMCU and Raspberry pi: IoT. International Research Journal of Engineering and Technology (IRJET), 6(4),5101-5105.

URL-2: https://www.instructables.com/id/NodeMCU-ESP8266-Details-and-Pinout/, (Erişim Tarihi: 10 Ocak 2020).

URL-3: https://randomnerdtutorials.com/esp8266-web-server-with-arduino-ide/, (Erişim Tarihi: 12 Ocak 2020).

URL-4: https://maker.robotistan.com/rc-servo-motor-nedir/ (Erişim Tarihi: 17 Ocak 2020). 